\title{
Relationship Between Obesity and Low Levels of Micronutrients among Elderly Patients Infected by SARS-CoV-2
}

\author{
Thiago José Martins Gonçalves* \\ Division of Nutrology and Clinical Nutrition, Sancta Maggiore Hospital, Brazil
}

Submission: March 29, 2021; Published: April 08, 2021

*Corresponding author: Thiago José Martins Gonçalves, MD, Division of Nutrology and Clinical Nutrition, Sancta Maggiore Hospital, Prevent Senior Private Health Operator, São Paulo, Lourenço Marques, 158 - Vila Olímpia, Brazil

\begin{abstract}
Abstrcat
The pandemic caused by 2019 novel coronavirus disease (COVID-19) emerged in Wuhan province, China, in December 2019, and has caused infections with varied clinical presentations, ranging from asymptomatic patients, mild flu syndrome to severe respiratory failure. Elderly individuals are part of the highest risk group for infection. In addition, it can be seen that many of elderly are obese and have multiple clinical comorbidities such as hypertension, diabetes and heart disease. Aging and obesity reduce levels of circulating micronutrients both due to the lower absorption of these nutrients by the digestive tract and the high consumption of some micronutrients due to the oxidative stress of the obese patient. Low levels of micronutrients among obese elderly people can aggravate the severe acute respiratory syndrome coronavirus 2 (SARS-CoV-2) infection and the disease may progress to orotracheal intubation and the need for mechanical ventilatory support. This mini review will show especially the relationship between low levels of vitamin D and zinc among elderly patients with obesity hospitalized with COVID-19.
\end{abstract}

Keywords: Obesity; Micronutrients; Elderly; COVID-19; SARS-CoV-2

Abbreviations: ACE2: Angiotensin Converting Enzyme-2; SARS: Severe Acute Respiratory Syndrome; VDR: Vitamin D Receptor; CT: Computed Tomography; ICU: Intensive Care Unit; ARDS: Acute Respiratory Distress Syndrome; WHO: World Health Organization

\section{Introduction}

In early December 2019, the fast propagation of a novel coronavirus broke out in Wuhan, Hubei, China, and caused a highly infectious serious acute respiratory syndrome named coronavirus disease 2019 (COVID-19) [1]. COVID-19 causes high morbidity and mortality worldwide, and the World Health Organization (WHO) officially declared it a pandemic in March 2020.

Obesity is very popular in most countries, especially in the United States with the incidence higher than 40\% [2]. It may lead to diabetes and heart disease, which are all associated with susceptibility or higher mortality of COVID-19. These remind us that obesity may be closely related to the aggravation of COVID-19. Obesity has been described as an independent predisposition factor for severe pulmonary infection [2]. Moreover, abdominal obesity is associated with impaired ventilation of the base of the lungs, resulting in reduced oxygen saturation of blood. Furthermore, the abnormal secretion of adipokines and cytokines like TNF-alpha and interferon characterize a chronic low-grade inflammation characteristic of abdominal obesity, which may impair immune response and have effects on the lung parenchyma [3]. Exploring the relationship between obesity and the severity of the disease is therefore of major clinical importance.

Furthermore, obesity could lead to severe conditions of COVID-19 in several possible ways such as: metabolic syndrome could cause damage to organs; increased expression of angiotensin converting enzyme-2 (ACE2), which would bind to the virus protein firmly and make adipose tissue a portal for virus invasion; state of overactivated inflammation and immune response, which may induce the excessive inflammatory response and immune exhaustion in COVID-19; obesity has increased abdominal pressure, limited chest expansion and movement, and insufficient respiratory compensatory function $[4,5]$.

Obesity also induced inflammation and insulin resistance in adipose tissue can further complicate the COVID-19. The resistance and the lipolytic effects of catecholamines and natriuretic peptide 
in obese patients mediated by a low amount of beta- 2 adrenergic receptors in adipocytes can lead to a reduction in the release of micronutrients stored in adipose tissue [6].

Clinical and subclinical micronutrient deficiencies common in older adults especially with obesity are known to contribute to decreased immune function and age-related diseases, implying that nutritional management is essential to reduce the risk of severe infection. In view of a lack of clinical data on preventive and/or therapeutic efficiency of the nutritive adequacy especially of zinc and vitamin D in COVID-19, this mini review aims to discuss the relationship between obesity and low levels of micronutrients among elderly patients infected by severe acute respiratory syndrome (SARS-CoV-2) and the role of these micronutrients in the protection against bronchopulmonary infections, as well as the existing indications of their impact on COVID-19.

\section{Discussion}

With the COVID-19 pandemic, nutrition is currently being discussed not only as a game changer for world health, but also when the nutrition is inadequate, as a potential source and reservoir for the emergence of viruses and development multiresistant bacteria [7]. An optimized nutritional status can have a range of effects on the activation of the immune system. A diet rich in proteins of high biological value, vitamins and minerals, such as lean meats, fruits, vegetables, legumes, nuts and olive oil, can have an influence on minor susceptibility to infectious diseases [8].

Recent studies have shown that low levels of micronutrients such as vitamin D and zinc, especially among elderly patients with obesity, have a greater potential in viral respiratory infections in previous deficient populations. Although the nutritional status of patients with COVID-19 has not yet been adequately studied, there is preliminary evidence that these disorders are associated with worse disease progression and outbreak, probably associated with a greater susceptibility to infection $[8,9]$.

\section{Vitamin D}

Vitamin D is a lipophilic hormone playing a key role in bone metabolism and calcium homeostasis, mainly acting by binding the vitamin D receptor (VDR), whose distribution involves almost all human tissues and cells. Recent data have also demonstrated potential modulation of extra-skeletal effects such as the immune system, cardiovascular diseases, insulin resistance and type 2 diabetes, conditions commonly linked with obesity [10].

Hypovitaminosis D is a common condition among elderly patients with obesity. Worldwide data show that $5 \%$ - $25 \%$ of the independent elderly population and $60-80 \%$ of institutionalized patients are deficient or insufficient in vitamin D [11]. Epidemiological studies reported that vitamin D deficiency represents an increasingly widespread phenomenon in various populations. Vitamin D deficiency is considered a clinical syndrome determined by low circulating levels of 25-hydroxyvitamin D (25-OHD), which is the biologically inactive intermediate and represents the predominant circulating form. Different mechanisms have been hypothesized to explain the association between hypovitaminosis D and elderly patients with obesity, including lower dietary intake of vitamin D, lesser skin exposure to sunlight, due to less outdoor physical activity, decreased intestinal absorption, impaired hydroxylation in adipose tissue and 25-OHD accumulation in fat $[10,11]$.

In the context of COVID-19, a recent retrospective populationbased study in Israel showed an association between vitamin D deficiency and greater likelihood of both COVID-19 infection and hospitalization in 14,000 analyzed individuals [12]. In another study in Belgium, $59 \%$ of the patients had vitamin D deficiency at hospital admission, and male patients with obesity had 25-OHD levels progressively lower with advancing radiological stage by chest computed tomography (CT), with disability rates increasing from $55 \%$ in stage 1 to $74 \%$ in stage 3 [13]

A recent study among critically ill patients infected by SARSCoV-2, shown a high prevalence rate of low serum concentration levels of 25-OHD (93.8\%) and nutritional diagnosis of obesity using body mass index (BMI $\geq 30 \mathrm{~kg} / \mathrm{m} 2: 68.7 \%$ ) among elderly patients admitted to the intensive care unit (ICU) [14]. According to this study, it is suggested that vitamin D deficiency should be investigated in the evolution of severe cases of COVID-19, especially in obese patients, requiring admission to the ICU and mechanical ventilation assisted by acute respiratory distress syndrome (ARDS). A systematic review investigated the relationship between concentrations of 25-OHD and risk of SARS-CoV-2 infection and COVID-19 severity. An increased risk of SARS-CoV-2 infection was observed in vitamin D deficiency and serum 25-OHD concentrations were lower in COVID-19 patients compared to healthy counterparts, such as indicated by combined results of both adjusted and unadjusted studies [15].

In conclusion, despite a lack of direct evidence of an effect of vitamin D status on COVID-19 infection, vitamin D deficiency is an easily modifiable risk factor and should be actively corrected through safe and readily available vitamin D supplements. However, it recognizes that specific high-quality data are needed to demonstrate the effectiveness of vitamin D supplementation in preventing COVID-19.

\section{Zinc}

Zinc is one of the most important essential micronutrients because it is involved in numerous biological functions and is considered a multipurpose trace element because of its ability to bind to more than 300 enzymes and 2000 transcriptional factors. It is widely involved in protein, fat and nucleic acid metabolism and gene transcription. Its role within the human body is extensive in reproduction, immune function, wound repair and, at the microcellular level, macrophage, neutrophil, natural killer cell and complement activity [16,17]. 
A low zinc intake by elderly has been documented in the National Health and Nutrition Examination Survey III (NHANES III); $35 \%-45 \%$ of elderly individuals ( $\geq 60$ years) were projected to be consuming zinc below the estimated average requirements ( $6.8 \mathrm{mg} /$ day for elderly females; $9.4 \mathrm{mg} /$ day for elderly males) [18]. Of clinical significance, low zinc levels have been associated with an increased susceptibility to infectious diseases, including viral infections and impaired activation and maturation of lymphocytes, disturbance of the intercellular communication via cytokines, weakening of the innate host defense and modulation of cytokine-induced epithelial lung cell barrier permeability [19]. Although zinc has direct antiviral properties, it is also critical in generating both innate and humoral antiviral responses. Zinc is an important cofactor of many viral enzymes, proteases, and polymerases, regulating cellular and systemic zinc distribution to inhibit viral replication and dissemination [20].

Also, indirect evidence indicates that zinc may decrease the ACE2, known to be the receptor for SARS-CoV-2. Improved antiviral immunity by zinc may also occur through up-regulation of interferon $\alpha$ production and increasing its antiviral activity. Zinc possesses anti-inflammatory activity by inhibiting NF- $\kappa B$ signaling and modulation of regulatory T-cell functions that may limit the cytokine storm in COVID-19 [21].

In view of the emerging global pandemic COVID-19 and the risk of progression in infected patients to severe cases of the disease, a Brazilian observational study shown a high prevalence of low zinc levels (79.6\%) among 269 admitted patients for the ICU, with $91.1 \%$ being elderly [22]. In addition, the study demonstrated an association between low zinc levels and the diagnosis of severe ARDS in critically ill patients (OR, 15.4; 95\% CI, 6.5-36.3; P <0.001). In an observational German study, Heller et al analyzed the zinc status of patients with COVID-19 and its relevance for predicting survival, as determined by the most common zinc biomarker used in clinical studies, that is, the total serum zinc concentration. The data indicated a profound and acute zinc deficiency in most patients with COVID-19 when admitted to the hospital and the samples from the non-survivors showed lower zinc levels than the samples from the survivors. In addition, an analysis of dynamic changes in serum zinc after hospital admission indicated an increase in zinc concentrations in both groups [23].

Zinc plays crucial roles in many aspects of life. In the course of infection, the immunomodulatory role of zinc is well evident. In the current pandemic of SARS-CoV-2, zinc supplement could play an important role to treat COVID-19 patients such as added immune boosting effects with anti-viral drugs and stopping SARS$\mathrm{CoV}-2$ replication in infected cells.

\section{Conclusion}

This mini review of the literature comprehensively summarizes the most relevant studies related to the clinical course and the management of COVID-19 among elderly patients with obesity and its relationship with low levels of micronutrients. Due to the lack of multiple therapies available and validated, most countermeasures depend on the use of containment approaches, public health quarantine and the recognition of preventable risk factors that may contain the spread and evolution of the disease. Importantly, maintaining an adequate nutritional state and a strengthened immune system with adequate serum levels of micronutrients may help the organism against infection by the new coronavirus, avoiding severe forms and the need for ICU and invasive mechanical ventilation. Therefore, micronutrient deficiencies should be quickly treated among elderly patients with obesity in the presence of SARS-CoV-2 infection.

\section{References}

1. Huang C, Wang Y, Li X, Ren L, Zhao J, et al. (2020) Clinical features of patients infected with 2019 novel coronavirus in Wuhan, China. Lancet 395(10223): 497-506.

2. Hales CM, Carroll MD, Fryar CD, Ogden CL (2020) Prevalence of Obesity and Severe Obesity Among Adults: United States, 2017-2018. NCHS Data Brief (360): 1-8.

3. Zhang X, Zheng J, Zhang L, Liu Y, Chen GP, et al. (2018) Systemic inflammation mediates the detrimental effects of obesity on asthma control. Allergy Asthma Proc 39(1): 43-50.

4. Yang J, Hu J, Zhu C (2021) Obesity aggravates COVID-19: A systematic review and meta-analysis. J Med Virol 93(1): 257-261.

5. Ryan PM, Caplice NM (2020) Is Adipose Tissue a Reservoir for Viral Spread, Immune Activation, and Cytokine Amplification in Coronavirus Disease 2019? Obesity (Silver Spring) 28(7): 1191-1194.

6. Zhang J, Hupfeld CJ, Taylor SS, Olefsky JM, Tsien RY (2005) Insulin disrupts beta-adrenergic signalling to protein kinase A in adipocytes. Nature 437(7058): 569-573.

7. Seifert G, Jeitler M, Stange R, Michalsen A, Cramer H, et al. (2020) The Relevance of Complementary and Integrative Medicine in the COVID-19 Pandemic: A Qualitative Review of the Literature. Front Med (Lausanne) 7: 587749.

8. Alwarawrah Y, Kiernan K, MacIver NJ (2018) Changes in nutritional status impact immune cell metabolism and function. Front Immunol 9: 1055 .

9. Fedele D, De Francesco A, Riso S, Collo A (2020) Obesity, malnutrition, and trace element deficiency in the coronavirus disease (COVID-19) pandemic: an overview. Nutrition 81: 111016.

10. Migliaccio S, Di Nisio A, Mele C, Scappaticcio L, Savastano S, et al. (2019) Obesity and hypovitaminosis D: causality or casualty? Int J Obes 9(1): 20-31.

11. Ross AC, Manson JE, Abrams SA, Aloia JF, Brannon PM, et al. (2011) The 2011 report on dietary reference intakes for calcium and vitamin D from the Institute of Medicine: what clinicians need to know. J Clin Endocrinol Metab 96(1): 53e8.

12. Merzon E, Tworowski D, Gorohovski A, Vinker S, Golan Cohen A, et al. (2020) Low plasma 25(OH) vitamin D level is associated with increased risk of COVID-19 infection: an Israeli population-based study. FEBS J 287(17): 3693-3702.

13. De Smet D, De Smet K, Herroelen P, Gryspeerdt S, Martens GA (2021) Serum 25(OH)D Level on Hospital Admission Associated With COVID-19 Stage and Mortality. Am J Clin Pathol 155(3): 381-388. 


\section{Current Research in Diabetes \& Obesity Journal}

14. Gonçalves TJM, Gonçalves SEAB, Guarnieri A, Risegato RC, Guimarães MP, et al. (2020) Prevalence of obesity and hypovitaminosis D in elderly with severe acute respiratory syndrome coronavirus 2 (SARSCoV-2). Clin Nutr ESPEN 40: 110-114.

15. Kazemi A, Mohammadi V, Aghababaee SK, Golzarand M, Clark CCT, et al. (2021) Association of Vitamin D Status with SARS-CoV-2 Infection or COVID-19 Severity: A Systematic Review and Meta-analysis. Adv Nutr 5: nmab012.

16. Baltaci AK, Yuce K, Mogulkoc R (2018) Zinc Metabolism and Metallothioneins. Biol Trace Elem Res 183(1): 22-31.

17. Lee SR (2018) Critical Role of Zinc as Either an Antioxidant or a Prooxidant in Cellular Systems. Oxid Med Cell Longev 2018: 9156285.

18. Ervin RB, Kennedy-Stephenson J (2002) Mineral intakes of elderly adult supplement and non-supplement users in the third national health and nutrition examination survey. J Nutr 132(11): 3422-3427.
19. Bao S, Knoell DL (2006) Zinc modulates cytokine-induced lung epithelial cell barrier permeability. Am J Physiol Lung Cell Mol Physiol 291(6): L1132-1141.

20. Chasapis CT, Ntoupa PA, Spiliopoulou CA, Stefanidou ME (2020) Recent aspects of the effects of zinc on human health. Arch Toxicol 94(5): $1443-1460$

21. Skalny AV, Rink L, Ajsuvakova OP, Aschner M, Gritsenko VA, et al (2020) Zinc and respiratory tract infections: Perspectives for COVID 19 (Review). Int J Mol Med 46(1): 17-26.

22. Gonçalves TJM, Gonçalves SEAB, Guarnieri A, Risegato RC, Guimarães MP, et al. (2021) Association Between Low Zinc Levels and Severity of Acute Respiratory Distress Syndrome by New Coronavirus SARSCoV-2. Nutr Clin Practx 36(1): 186-191.

23. Heller RA, Sun Q, Hackler J, Seelig J, Seibert L, et al. (2021) Prediction of survival odds in COVID-19 by zinc, age and selenoprotein P as composite biomarker. Redox Biol 38: 101764.

Your next submission with Juniper Publishers
will reach you the below assets
- Quality Editorial service
- Swift Peer Review
- Reprints availability
- E-prints Service
- Manuscript Podcast for convenient understanding
- Global attainment for your research
- Manuscript accessibility in different formats
( Pdf, E-pub, Full Text, Audio)
- Unceasing customer service
Track the below URL for one-step submission
https://juniperpublishers.com/online-submission.php

